\title{
Nas trilhas da escrita ensaística de Lem: anotações do tradutor
}

Henryk Siewierski

\begin{abstract}
Resumo: O artigo apresenta as anotações à margem do trabalho de seleção e tradução dos ensaios de Stanisław Lem para o português, iniciado em 2014. Resultantes da convivência com a obra do autor e seus contextos, da reflexão durante a leitura e tradução, as anotações apontam diversos temas e ideias da obra ensaística deste clássico da Ficção Científica do século XX, considerado também inovador do ensaio científico pelo uso singular de recursos literários.
\end{abstract}

Palavras-chave: Stanisław Lem, ensaio científico, fiçãa científica

Conhecido como autor de Solaris e outras obras em que a ficção e a ciência coabitam de forma singular, Stanisław Lem (1921-2006) atraía e continua atraindo leitores e tradutores. Os seus ensaios sobre diversos temas de ciência, tecnologia, filosofia, literatura e civilização contemporânea atraem menos os tradutores, embora justamente o ensaio Lem considere a sua principal forma de expressão e seja considerado um inovador do ensaio científico ou até um inventor de sua nova forma pelo uso singular de recursos literários.

Na obra ensaística de Lem destacam-se: Summa technologiae (1964), uma análise e avaliação das possibilidades que surgem com as novas tecnologias de produção e de amplificação das capacidades humanas; a Filosofia do acaso (1970), uma espécie de "summa litteraturae" que, mostrando as possibilidades que se abrem com a aplicação da teoria dos jogos na descrição dos fenômenos físicos, biológicos, cósmicos e culturais, propõe uma "teoria empírica da literatura"; O Fantástico e a futurologia (1970), que trata da história, da teoria e da crítica da science fiction.

Nos últimos anos de sua vida, Lem revisita a temática dessas obras nos ensaios publicados nos livros O segredo do quarto chinês (1996), Sex Wars (1996), 
Bomba de megabyte (1999) e Piscar de olho (2000), fazendo abordagens críticas a partir de novos avanços da ciência, da nova fase de desenvolvimento tecnológico, dos novos horizontes do conhecimento, em confronto com a realidade vivida e com suas consequências para o futuro da cultura e civilização humana. No decorrer desse tempo algumas das suas ousadas visões futurológicas passaram do campo da ficção para a realidade. O poder da razão humana surpreende, mas também gera uma crise de confiança diante dos perigos em que os seus sucessos colocam o homem e o planeta, diante dos sinais da decadência e da crise dos valores éticos. Lem, autor da Summa technologiae alaborada no espaço das hipóteses e modelos abstratos da ciência, com o passar do tempo chega cada vez mais a confrontar as conquistas e as perspectivas do desenvolvimento científico e tecnológico com a situação do mundo real, com a condição humana, com as perspectivas, perigos e desafios do homem em sua relação consigo mesmo e com o Universo.

$O$ tradutor que geralmente atende às demandas das editoras, precisa às vezes dar de presente a si mesmo um projeto próprio, esquecer da bolsa de valores dos best sellers, das leis do cânone, eleger o original por conta própria e fazer a tradução, que é uma forma de leitura bem individual, o que não quer dizer egocêntrica, se a sua razão de ser é também o outro leitor - o destinatário da obra traduzida.

Este é o caso do projeto de seleção e tradução de ensaios de Lem, iniciado em 2014. A tradução prossegue, mas não é só o seu produto final que importa. À margem do processo de tradução, proliferam seus produtos secundários, textos precários, fragmentários, registrados ou não, resultantes da convivência com a obra e seus contextos, do diálogo, da reflexão, ou simplesmente da vontade de compreendê-la melhor, de anotar e guardar ideias, expressões, pensamentos. Pode ser que depois sirvam para elaboração de um estudo introdutório à antologia dos ensaios ou não sirvam mais para nada. Mas, encontrando um lugar nesse Caderno de Literatura em Tradução, podem, quem sabe, ainda servir um dia a alguém interessado na obra de Lem como um testemunho da sua tradução e leitura ${ }^{1}$.

\section{1.}

Quanto mais leio e releio as "teorias de tudo" de Lem - Summa technologiae e Filosofia do acaso -, tanto mais complexa, contraditória e difícil de ser resumida

1 As anotações que seguem foram escritas durante o estágio pós-doutoral realizado na Universidade de Cracóvia, no primeiro semestre de 2015, com bolsa do CNPq, destinada ao estudo e tradução da obra ensaística de Stanisław Lem. 
me parece a sua visão do mundo, das evoluções biológica e tecnológica que comparava e em que encontrava semelhanças. A mania ou a virtude de abarcar todo o conhecimento e relacionar tudo com tudo, produz as generalidades de efeito, ousadas e atraentes, mas ao mesmo tempo muitas digressões, hipóteses alternativas e laterais que põem em questão o que se apresentava como uma revelação quase epifânica ou prometeica. Lem domina, portanto, esta arte de ensaio em que - segundo T.W. Adorno - se revela a curiosidade e a "ingenuidade de estudante" e não a obediência aos paradigmas do método científico (ADORNO, 1994, p. 167-187).

Ensaio como esse é difícil de resumir, mas onde o resumo (e a razão?) falha, resta a tradução e/ou uma exploração parcial de leitura do seu potencial cognitivo e dialógico. É como se “irresumíveis", os grandes ensaios de Lem fossem escritos para serem apenas percorridos, pensados, traduzidos.

Se compararmos esses volumosos e complexos ensaios de Lem da sua primeira fase ensaística com os ensaios posteriores (mas também com numerosas entrevistas e cartas), curtos e com as mensagens e conclusões bastante unívocas, podemos supor que, no decorrer da sua vida, o autor de Summa technologiae e outras "summas" percebe a necessidade de deixar mais claros os resultados dos seus jogos e explorações nos territórios da ciência, como diagnoses ou/e avisos diante dos rumos presenciados e vislumbrados da civilização.

\section{2.}

Ler Lem como Lem lê a ciência, ou seja, com a dedicação suficiente não somente para conhecer o melhor possível suas descobertas e seus limites, mas também com distanciamento de quem a trata apenas como um subsídio em busca das respostas a seus próprios questionamentos, seu pensar a vida e o mundo, um instrumento, portanto, das tentativas de resolução dos problemas de natureza filosófica. Diferentemente dos cientistas que só às vezes saem dos seus laboratórios para ver como está o mundo e transmitir aos profanos, de uma forma mais acessível, os resultados de suas pesquisas, Lem imerso na vida, grato hóspede dos seus vastos domínios, livre de compromissos de especialista, percorre os laboratórios, curioso e cético ao mesmo tempo, espreitando o que se pode aproveitar na busca das respostas às perguntas com que a vida nos desafia. Ler Lem com pretensão de se tornar especialista em Lem seria praticar um pedantismo estranho a sua obra e seu pensamento. 


\section{3.}

Stanisław Lem nasceu no ano de 1921, em Lvov, numa familia de judeus poloneses, sobreviveu à Segunda Guerra, viveu na Polônia comunista, depois capitalista, viajou pouco e morreu na cidade de Cracóvia, em 2006. Em vez do esboço biográfico mais completo, um pequeno autoretrato compilado de fragmentos das cartas de Lem, trocadas com seu tradutor americano Michael Kandel:

Nasci e fui criado numa familia abastada, porque o meu pai era em Lvov um médico muito procurado, bom especialista (...). Depois vieram os tempos para nós duros - de guerra. (...) Depois da guerra vivemos em condições muito modestas, mas não miseráveis (...). Depois da guerra, nos anos 19451947, enquanto estudava medicina, fui mantido, já com 26 anos de idade, por meu pai, e então comecei a ganhar escrevendo, no início muito pouco. E tive a sensação de que não estava totalmente certo ao escrever bobagens sensacionais para as, ainda existentes naqueles anos, editoras particulares. (Carta a Michael Kandel, de 2 de abril de 1987. LEM, 2013, p. 636)².

Comi o meu pão de muitos fornos; traduzi os livros de russo sobre a alimentação do gado, para ganhar dinheiro; fui assistente "para tudo" num Conversatório da Uniwersytet Jagielloński; consertava os automóveis nos tempos de guerra alemã (muitas vezes destruía-os, quando dava), fui soldador (fraco), médico, crítico, jornalista, revisor de textos, autor dos artigos de medicina... e não acho que algo disso tivesse sido um puro desperdício de tempo. Pois tudo se armazena em algum lugar. Sei também que a experiência de vida é, a princípio, intransmissível (é possível ver a literatura como uma tentativa, quase fracassada, de transmissão daquela experiência pessoal de modos NÃO DISCURSIVOS). (Carta a Michael Kandel, de 30 de setembro de 1976. LEM, 2013, p. 501).

Numa carta a Kandel, de 25 de outubro de 1976, Lem comenta o recebimento de exemplares dos livros escolares para $6^{\mathrm{a}}$ e $10^{\mathrm{a}}$ série, da República Federal da Alemanhã, em que estavam incluídos os seus contos:

Se nos anos quarenta alguém tivesse me dito que depois da guerra eu seria escritor, acreditaria; se me profetizasse o Prêmio Nobel, talvez iria acreditar também, pois a vaidade humana parece não ter limites. Mas se aquele profeta me tivesse comunicado que os mesmos alemães, que me queriam matar

2 A tradução desta e de outras citações que seguem é do autor. 
como se eu fosse uma barata, iriam ensinar seus filhos o alemão dos meus contos - não, disso, juro, não acreditaria (LEM, 2013, p. 509).

\title{
4.
}

Philip Kindred Dick, clássico da ficção científica americana, achava que Stanisław Lem era personagem fictício, criado pelos comunistas. O seu nome, estranho e atípico nas línguas eslavas seria uma sigla de um grupo secreto que produzia livros por encomenda do partido, com a finalidade de exercer o controle da sociedade. Uma prova desta tese seria também a diversidade dos estilos da obra de Lem. Dick chegou a escrever, em 1974, uma carta com esta denúncia ao FBI. Lawrence Sutin, na sua biografia de Philip K. Dick, Divine Invasions, reconhece que o seu personagem biografado era uma pessoa esquisita, mas assegura que não se tratava de um doente mental. Tal esquisitice, ou mais do que isso, pôde observar Lem quando, depois da publicação da tradução polonesa de Ubik, romance por ele recomendado e posfaciado, foi acusado pelo seu autor... citemos o que diz próprio acusado na carta a seu tradutor americano Michael Kandel:

\begin{abstract}
Ph. Dick, um autor dos EUA, publicou uma carta aberta no "Forum" (órgão da SF Writers), em que me chama de canalha, ladrão, aproveitador, porque segundo ele fiz na Polônia uma edição pirata de Ubike (ele deve ser um louco, porque não é verdade, e mesmo se quisesse, a editora polonesa, como a empresa estatal, não poderia publicar nada sem um contrato juridicamente válido). Ao mesmo tempo, numa primeira resenha, alguém chamou o Ubike de grafomania. Eu precisava disso!! Mas não deixa de ser engraçado (LEM, 2013, p. 428).
\end{abstract}

Lem começa o seu posfácio de Ubik com uma diagnose da SF americana, denunciando a sua mediocridade e mistificação ${ }^{3}$. Insuficiente como reflexão sobre o futuro e a civilização, sobre a posição que a Razão ocupa no Universo, ela tem, ao mesmo tempo, pretensões de representar as alturas da arte e do pensamento. Porém, às críticas do seu primitivismo, responde apresentando-se como um gênero de diversão.

$\mathrm{Na}$ paisagem assim uniformizada da SF americana Lem destaca Ph. Dick, que mesmo utilizando os motivos e requisitos gastos do gênero (telepatia, guer-

3 DICK, Philip K. Ubik. Tradução de Michał Ronikier. Posfácio de Stanisłam Lem. Kraków: Wydawnictwo Literackie, 1975. 
ras côsmicas, viagens no tempo, catástrofes e fins do mundo), quebra em seus romances as convenções que exigem uma racionalização dos acontecimentos improváveis e incompatíveis com a lógica e realidade empírica. Nos seus romances as causas das transformações e catástrofes não são identificadas, permanecendo misteriosas e irreconhecíveis. Mesmo explorando um gasto arsenal do kitsch da SF americana, Ph. Dick não se enquandra nele e ganha simpatia de Lem como quem, solitário, enfrenta com a sua imaginação "o excesso das oportunidades" com que nos desafia o cosmos e a cultura.

Lem chama a atenção para a obra de Ph. Dick ainda antes da edição polonesa de Ubik. Na sua monumental teoria e crítica da ficção cientítica, O fantástico e a futurologia (1970), dedica a ele um capítulo que termina com essas palavras:

Dick é na SF como um visitante de completamente outras esferas, cujos pensamentos, desejos, dilemas ele incorporou no que esse terreno dispunha, aproveitando os trajes do kitsch, para com eles - feito um mimo no depósito dos trapos - representar o drama do mistério da existência (LEM, 203, vol. 1, p. 173).

\section{5.}

Estou na Nuvem de Magalhães. A nave atravessa espaços siderais... Mas a mim me leva às naves espaciais da minha infância, construídas debaixo da mesa, separadas do resto do quarto com cobertor, com cadeiras viradas, almofadas e instrumentos de navegação trazidos da cozinha para dentro. Foi um espaço minúsculo, mas seguro, espaço de intimidade e, ao mesmo tempo, espaço da possível e desejada ligação com os outros mundos como que prometidos ao recém-chegado neste planeta Terra. Podia ser justamente no ano em que Lem escrevia este conto, a poucos quilômetros do lugar onde eu morava. Poucos anos depois, já aluno da quarta ou quinta série, com dois colegas meus de turma nos reuníamos no início da noite, num jardim da casa de um deles, para observar o céu, planejar a construção de um telescópio e, em seguida, de um foguete que nos levaria numa viagem espacial rumo à Lua e às estrelas. Mas o fim da infância chegou rápido demais para que pudéssemos realizar esses planos. Mesmo abandonados, eles merecem ser lembrados. E mais do que lembrados: tomados com seriedade, a mesma com que a criança brinca. O Professor Hogarth, personagem do romance Voz do Mestre, de Lem, cujas ideias tem muito a ver com as do autor ${ }^{4}$, sabia disso:

4 "Professor Hogarth do Voz do Mestre, sou eu, num certo sentido". Carta a Michael Kandel de 28 de outubro de 1976. LEM, 213, p. 513). 
Cada criança realiza espontaneamente descobertas, das quais surgiram mundos de Gibbs e Boltzmann, porque a realidade se lhe apresenta como a multiplicidade das possibilidades, tão fáceis de discernir e concretizar como que em atos espontâneos. A criança está rodeada da pluralidade dos mundos virtuais, o cosmos de Pascal lhe é completamente estranho, feito um cadáver rígido do relógio em andamento, num movimento cadenciado. Depois, a ordem petrificada da idade madura destrói esta riqueza primordial (LEM, 1968, p. 17).

Ler Lem hoje não seria encontar uma prova de que ainda nem tudo foi perdido daquela idade da bendita "ignorância" que dava tanta liberdade e tanto poder à imaginação?

\section{6.}

A filosofia do acaso (1968) declara a guerra às teorias fenomenológica e estruturalista da obra literária. A poética de ensaio fornece armas diversas, também leves, mas capazes de causar estragos graves no campo do adversário:

Sobre o modo de ser da obra literária quando não emitida nem recebida, nada sabemos. A obra já lida não é obra objetiva, no mesmo sentido em que a lembrança de um amigo não é um amigo objetivo. As perguntas acerca das obras não lidas são da mesma espécie que as perguntas acerca do sabor do açúcar depois da terceira guerra mundial ou acerca da existência das máquinas de escrever no Paleolítico inferior. (...) É possível investigar as obras literárias como certas enunciações linguísticas, até com os meios puramente formais, contando, por exemplo, a frequência das palavras etc., mas sobre o texto enquanto obra literária, isto vai nos dizer exatamente quanto iremos saber sobre a beleza de uma estrela de cinema investigando os átomos, íons e elétrons do seu corpo (LEM, 2010, p. 53-54).

Independentemente de Jauss e pararelamente ao primeiro manifesto da estética da recepção, História da literatura como provocação (1970), A filosofia do acaso anuncia uma nova corrente dos estudos da literatura, centrados na perspectiva do leitor e antiessencialistas. Familiarizado com as ciências exatas, Lem denuncia e ridiculariza as pretensões cientificistas dos Ingarden e Todorov, que, ao tratarem a obra literária como objeto, ignoram a sua vida em diálogo com o público leitor, que muda com os contextos históricos, sociais, culturais. Nesta vida o papel do acaso é tão relevante e necessário, como na vida e na sua evolução em geral. A obra 
está em movimento, lida e interpretada, entre os leitores e entre outros textos, em diferentes espaços, muda com os tempos e as vontades imprevisíveis. Por exemplo: "Ao escrever Colônia penal, Kafka não tinha em mente os campos de extermínio hitlerianos, porque antes da primeira guerra mundial não existiam. Mas nós, não podemos ignorá-los, lendo hoje este conto"

\section{7.}

Leio Lem. Leio no ebook o que ele escreveu há vinte anos, vislumbrando a expansão da internet ao ponto de chegar o dia em que

uma pessoa ficando em casa possa ter acesso a todas as bibliotecas do mundo, inclusive videobibliotecas, entregar-se a um intenso intercâmbio intelectual com inúmeras pessoas graças a aperfeiçoado e-mail, correio eletrônico, ver obras de arte (...), desenvolver uma intensa atividade econômica (...), paquerar (...), ver paisagens dos países distantes... e assim por diante, pode tudo sem nenhum risco (a não ser financeiro)... mas com tudo isso permanece na solidão (LEM, 1996, p. 139).

Vislumbrando assim as mirabolantes perspectivas da comunicação eletrônica e do acesso à informação, Lem alertava sobre os efeitos colaterais da substituição do natural pelo seu sucedâneo artificial na esfera de relações humanas. A perfeição e os encantos da eletrônica a serviço da comunicação não substituem a necessidade de uma autêntica relação entre as pessoas. A ilusão provocada pela oferta dos meios que prometem alargar e intensificar contatos com o outro e o mundo todo, pode levar a uma solidão em meio à multidão do mundo virtual. No entanto, podem também amenizar a solidão, a separação.

\section{8.}

Seríamos apenas hospedeiros da Razão? Toda a humanidade hospedando, ao longo da evolução biológica, essa passageira, que um dia pode se desprender, emancipar-se, e, sem precisar mais do frágil corpo humano, seguir alem da dor, alem do Bojador do universo? Uma parasita? Uma estranha disfarçada de companheira fiel e inseparável? Fala Golem, supercomputador do futuro, dirigindo-se aos homens:

5 Cit. por JARZĘBSKI, Jerzy. „Byt i Los”. In: LEM, 2010, p. 596. 
A evolução não visava nem vós particularmente, nem outros seres, pois o que contava não eram quaisquer seres, mas só o famigerado código. $\mathrm{O}$ código genético é uma mensagem articulada sempre de novo e só essa mensagem conta na Evolução - e, na verdade, ela mesmo é a Evolução. O código está engajado numa produção periódica de organismos, porque, sem o seu suporte periódico ele iria se desintegrar num incessante ataque browniano da matéria morta (LEM, 1981, p. 35).

Podemos ser apenas veículos do Código capaz de elevar a Razão, através de suas inúmeras encarnações até o estágio em que não precisará mais do corpo biológico para seguir a sua Odisséia cósmica ou para administrar os domínios extraterrenos. Nos descartará ou tomará conta de nós? Anthropic Principle - o termo anticopernicano cunhado em Cracóvia mesmo, por Brander Carter, durante sessão comemorativa de Copernicus, em 1973 - podemos substituir por Robotic Principle, ou seja, a ideia de que tudo desde o princíprio trabalhava para o surgimento de uma máquina pensante, onipotente, Espirito ex máquina, que, com um pouco de boa vontade e sentido de humor, não passaria de mais uma, não muito heterodoxa teodicéia.

9.

A hipótese do "gene egoísta", Lem formula antes de Richard Dawkins ter lançado o seu The Selfish Gene (1976). Egoísta porque trata organismos como o veículo de sobrevivência, preocupando-se só da sua própria vida eterna. Mas, como o processo de transmissão do código genético nem sempre é perfeito, ocorrem erros, e assim o processo da evolução pode prosseguir, organismos ficam alterados, uns perdem o trem, outros seguem a viagem a serviço do código egoísta e persistente. Até que numa etapa tardia da criação biológica aparece a Razão. Aqui, Lem apresenta uma hipótese que destoa da nossa humana, muito humana presunção: a Razão não é tanto o coroamento da marcha da evolução biológica, quanto um recurso, uma força que surge para socorrer os seres frágeis e defeituosos dos estágios avançados da evolução biológica, seres ameaçados de extinção. Foram os humanos a desenvolver mais este recurso, criando línguas étnicas e culturas, que levam à fabricação da inteligência artificial. No Golem XIV Lem antecipa o momento em que a humanidade, ao produzir uma inteligência artificial superior ao intelecto humano, terá que decidir: ou os homens deleguem às máquinas o gerenciamento da sua existência e do seu destino, condenando-se assim à auto-degradação e submissão, ou evoluem transformando a sua própria 
natureza com os meios da engenharia capazes de colocá-la no patamar mais alto, superar os hiper-cérebro eletrônicos, e assim proporcionar condições para a expansão cósmica e ilimitada da Razão.

10.

Até que ponto as ideias de Lem são marcadas pelo "gnosticismo tecnológico", como o define Hermínio Martins?

A tecnologia leva à manipulação do mundo material e por isso deixa a impressão de que é contrária à gnose. Porém, com a expressão aparentemente paradoxal - "o gnosticismo tecnológico" -, está definida aqui a relação das realizações, aspirações e projetos tecnológicos com um sonho, próprio da gnose, de ultrapassar os limites da condição humana (MARTINS, 1993, p. 229).

É possível mostrar, que em suas ideias, Lem se aproxima de vez em quando do gnosticismo tecnológico no sentido aqui definido. Aproxima-se, mas sem permanecer nesta posição - por dois motivos: por seu ceticismo quanto à possibilidade de definir os últimos fins da humanidade; e por seu ceticismo quanto à capacacidade do homem de usar os meios tecnológicos só para o bem de sua espécie. Lem não é um humanista que prega a superioridade do homem acima de tudo, pois existe algo que o supera e transcende: a Vida.

Assim muitas vezes clamava, dava conselhos, como no deserto, para que a Ciência tornasse a imitar, através dos processos de pesquisa, a Vida como Tecnologia. No final da Summa technologiae, escrevo, que os aminoácidos, a língua proteíno-nucleotídea criam os baobás, vírus, macacos, crocodilos, algas, filósofos, enquanto a nossa língua humana só cria filosofias (LEM, 2009, p. 111).

Ao se aproximar do fim sua vida, o autor da Summa technologiae podia ver como as Ciências seguiam os rumos por ele preconizados, mas também podia observar a mediocrização nos usos das conquistas tecnológicas, que tanto o irritava, e certamente não contribuía para reforçar as suas passageiras inclinações gnósticas. 


\section{1.}

Agnóstico declarado, racionalista, criador dos seres superiores aos humanos (mas não necessariamente sobrenaturais), dos deuses hipotéticos, "deuses defeituosos", também luciféricos, outros mundos, fenômenos misteriosos ainda inexplicáveis... Lem de modo algum entra em guerra com a religião; ao contrário, precisa dela e, em sua obra, explora bastante os temas metafísicos, criando hipóteses, inclusive, da vida eterna (geralmente em forma caricatural, que lembra histórias grotescas de Wolter), mas deixa claro que está no território em que Deus para ele não existe, território de quem por opção não acredita no que lhe parece irracional e contraria os dados empíricos. Os deuses são para se acreditar ou não neles e, acreditando, para adorar e não justificar filosoficamente ou cientificamente a sua existência. Para Lem basta ser inconciliável a sua existência com a razão e com a experiência, e também com o sofrimento onipresente na evolução da vida e na história do homem, para se colocar na posição de quem não acredita.

\section{2.}

Como é possível os seres que além do canal de transmissão genética em cromossomos, possuem um canal de transmissão à parte, o de cultura, independente do canal genético, serem incapazes de avistar qualquer aprendizagem da sua história banhada em sangue? (LEM, 2009, p. 106).

A pergunta pode parecer ingênua, mas não é. Porque mesmo que Lem não tenha ilusões quanto ao potencial destrutivo que herdamos em cromossomos, não se rende ao destino, discute com ele, diferentemente de Leminski ("Não discuto com o destino / o que mandar eu assino"). Se mesmo na evolução biológica há lugar para o acaso, uma adesão ao determinismo histórico parece dificilmente justificável. Considerando os estragos que tem provocado ao longo dos tempos, merece tanto uma rejeição, quanto a ridicularização, como nesta confissão referente ao autor da Fenomenologia do Espirito: "Eu não suportava Hegel, não conseguia lê-lo, por ele estar tão convencido de que o próprio Absoluto falava por ele para a maior glória do Estado prussiano". Quem confessa é professor Hoghard, personagem hetoronímica de Lem, no seu romance Glos Pana (A voz do Mestre) (LEM, 1968, p. 122). 


\section{3.}

Traduzo Provocação de Lem, uma provocante radiografia do hitlerismo e, do seu "sucessor", o terrorismo contemporâneo. Traduzo em Cracóvia, cidade de Lem, na primavera de 2015. Clima tenso da campanha das eleições presidenciais. Nenhum dos candidatos que, em nome do "bem da nação", atacam seu adversário apontando com "justa indignação" seus erros, culpas, perigos, caso seja eleito, imagina que está dando corda ao radicalismo cujo parentesco com o terrorismo, nem sempre visível, existe. Estamos numa democracia, mas uma democracia frágil no século em que o terrorismo internacional conta com aliados poderosíssimos. As críticas acirradas e muitas vezes exageradas dos defeitos e imperfeições no funcionamento da democracia, a demonização dos adversários na corrida pelo poder, além de terem marcas anacrônicas das lutas do tempo da ditadura, podem servir - sem querer - como reserva de combustível para os extremismos de hoje.

Cada autêntico movimento de oposição que tem os motivos sólidos para a luta na situação de uma verdadeira opressão ou exploração, externamente parecido com o extremismo pseudopolítico, favorece sem querer os falsificadores que apresentam o assassinato como o instrumento de luta pelo bem, uma vez que aumenta a confusão reinante na análise das ocorrências e dificulta, senão impossibilita, a distinção entre as culpas aparentes e verdadeiras. Mas quem e em que lugar neste mundo está angelicamente sem culpa até o fim? E assim surge o jogo de mímica, surpreendentemente eficaz. Se a razão simulada não se distingue da razão sincera, não é tanto em virtude da perfeição dos simuladores, mas por não ser totalmente limpa a consciência das sociedades que engendraram o terrorismo de pós-guerra (LEM, 1951, p. 50-51).

\section{4.}

Faz parte da Filosofia do acaso o ensaio "Os limites do crescimento da cultura", em que a casualidade nos processos da evolução da cultura é reconhecida com todos os seus efeitos benfazejos, como promotora da diversidade e do crescimento, mas também como geradora do caos e da cacofonia.

A dinamicidade da cultura se resume a uma realização seletiva dos valores. A questão é como acontece esta seleção. Ela não pode ser casual. Quando os crescimentos são casuais, quando a casualidade domina a emergência e o declínio dos valores professados só momentaneamente, a cultura vira 
uma polpa vibrante, sem capacidade de formar e consolidadar as atitudes humanas. A mutabilidade subcultural não é uma esperança da cultura, mas a sua enfermidade, não um indicador de caminho, mas um sintoma, uma reatividade e não atividade, um resultado de desorientação e não uma proposta orientadora (LEM, 2010, p. 336).

A cultura não é o elemento da natureza equipada em mecanismos de controle do caos. Na cultura cabe aos homens reconhecer e cuidar dos valores que garantem a sua estabilidade, exercer o controle e a orientação, estabelecer limites, para que a casualidade não leve à desintegração. Cabe ao homem, mas até que ponto ele vai dar conta do recado? A resposta de Lem não é muito animadora.

\section{5.}

As suposições dos evolucionistas de que o homem introduziria na sua cultura as suas características biologicamente herdadas, com o potencial de agressividade talvez em primeiro lugar, sempre provocavam e continuam provocando uma grande indignação dos melhoristas formados em humanidades (LEM, 1988, vol. 2, p. 53).

Lem gosta de contar a história em que encefalização, ou seja, o processo de formação da inteligência humana esteja relacionada com o carnivorismo. É a história contada também pelos cientistas como Edgar Morin (Oparadigmaperdido), Robert Andrey (African Genesis) ou Robin Fox (The Imperial Animal). Há cerca três milhōes de anos a prole dos proto-homens vegatarianos se divide em dois ramos: os australopitecos mansos que nem matariam uma mosca (para comer) e seus primos carnivoros que os venceram numa luta fratricida e canibalesca. Há também hipótese que os mansos desapareceram por não se adaptarem as mudanças climáticas, a desertificação africana, ao contrário dos outros, que mudaram a opção alimentícia partindo para caça (o que era mais inteligente e que com o tempo fez aumentar cada vez mais a inteligência). São só hipóteses, há outras, mas o fato é que a nossa herança genética não facilita o trabalho dos construtores das utopias.

\section{6.}

Lem não descarta a possibilidade de existência da vida e dos seres racionais (não necessariamente nos moldes da mesma lógica e matemática) nos outros 
planetas, inclusive em formas mais avançadas do que na Terra. O fato de não conseguirmos estabelecer o contato com outros habitantes do Cosmos significa só a impossibilidade desse contato diante da imensidão do espaço e do tempo em que a evolução e o declínio da vida e das civilizações só pode ser um ciclo de duração comparável a um piscar de olho. O silêncio do Cosmos não pode ser visto como uma prova de que somos sozinhos no Universo, só que o contato com os outros só pode ocorrer no espaço da ficção, e é a possibilidade que Lem explora até exaustão. Para quê? Para divertir seus leitores, com certeza. Mas não só. Também, e talvez antes de tudo, para com estas histórias de relações interplanetária representar as relações inter-humanas, geralmente nada edificantes, e merecedoras mais das técnicas de panfleto, sátira, grotesco, do que da epopéia. No contato com o outro, com o misterioso, o inconcebível, revelam-se as limitações dos homens que no fundo não estão dispostos a dialogar e interagir; na verdade, querem somente se expandir, como confessam os emisários da humanidade surpreendidos por uma forma de vida diferente no planeta Solaris:

de modo algum queremos conquistar o Cosmos, só queremos alargar a Terra até os seus limites (...). Consideramo-nos cavaleiros do santo Contato. É outra mentira. Não procuramos ninguém a não ser outros humanos. Não precisamos de outros mundos. Precisamos de espelhos (LEM, 1968, p. 74).

Em outros contatos com os extraterrestres revela-se, antes de tudo, a agressividade dos humanos. Por exemplo, a decifração de uma mensagem do Cosmos, enviada pelos seres inteligentes atraves do raio pulsante de neutrino, logo faz surgir uma ideia de utilizá-la para produção de uma super arma, que permite transferir a reação nuclear para outro lugar, longe de onde foi efetuada (romance $A$ Voz do Mestre). No último romance de Lem (Fiasco), a expedição para o planeta Quinta, em que foi detectada a vida e uma civilização avançada, termina com a destruição desse planeta pelos humanos, inconformados com as dificuldades de comunicação e falta de uma receptividade esperada da parte dos Quintanos (Fiasco).

\section{7.}

Kurt Vonneguth escreveu: "Para mim Lem é o mestre de pessimismo incurável, vislumbrando com susto o que a humanidade tresloucada pode ainda aprontar, caso sobreviva". Ao mesmo tempo, ele reconhecia o sentido de humor 
do autor de Solaris, que aprendeu a fazer caretas e palhaçadas "só para a sua assustadora visão do futuro pudesse parecer fingida para o leitor" (VONNEGUT, 1989, p. 24, 26).

\section{8.}

Numa das cartas a seu tradutor americano Michael Kandel, Lem confessa de ter reunido nos últimos anos pastas cheias de coisas inacabadas e abandonadas por lhe parecerem demasiadamente "sophisticated". Questiona o direito de exigir de quem quer que seja a decifração de seu textos complicados, produtos de máquina de "superestilização", formando um "labirinto linguístico", mesmo sabendo que não faltam apreciadores e entusiastas dessa sofisticação. Mas ele questiona a autenticidade desta apreciação, deste entusiasmo. E parece ter certa razão.

sei, no entanto, que os que se tornaram lemólogos e lemófilos, permanecem "de plantão de encanto" mesmo com tamanha complicação dos meus textos... mas será que eles possam se deliciar com ela de verdade? Não vão projetar no meu texto as suas antecipações? Ao ler recentemente uma pilha de resenhas italianas, em que o meu Eden estava a ser elevado ao pedestal do "roman philosophique", e onde se insistia que o meu Retorno das estrelas tinha valores épicos, fiquei com tanta vergonha que não consegui ler até o fim (Carta a Michael Kandel de 23 de fevereiro de 1978. LEM, 2013, p. 628).

Seria uma pitada de modéstia de quem não costumava pecar por ela? Ou uma vaidade disfarçada? Ou apenas uma prova de que não faltava a Lem o sentido de humor?

\section{Referências}

ADORNO, Theodor W. "O ensaio como forma”. In: Theodor W. Adorno. Gabriel Cohn (ed.), tradução de Flávio R. Kothe. São Paulo: Ática, 1994.

DICK, Philip K. Ubik. Tradução de Michał Ronikier. Posfácio de Stanisław Lem. Kraków: Wydawnictwo Literackie, 1975.

JARZEBBSKI, Jerzy. „Byt i Los”. In: LEM, Stanisław. Filozofia praypadku. Warszawa: Biblioteka Gazety Wyborczej, 2010.

LEM, Stanisław. Fantastyka i futurologia. Posłowie Jerzy Jarzębski. Vol. 1-2. Kraków: Wydawnictwo Literackie, 2003. 
LEM, Sanisław. Filozofia praypadku. Literatura w swietle empirii. Warszawa: Biblioteka Gazety Wyborczej, 2010.

LEM, Stanisław. Filozofia praypadku. Kraków: Wydawnictwo Literackie, 1988.

LEM, Stanisław. Głos Pana. Warszawa: Warszawa: Czytelnik, 1968.

LEM, Stanisław. Golem XIV. Kraków: Wydawnictwo Literackie, 1981.

LEM, Stanisław. Solaris. Nięwycię̇ony. Kraków: Wydawnictwo Literackie, 1968.

LEM, Stanisław. Prowokacja. Kraków: Wydawnictwo Literackie, 1951.

LEM, Stanisław. Sex Wars. Warszawa: Biblioteka Gazety Wyborczej, 2009.

LEM, Stanisław. Stawa i fortuna. Listy do Michaela Kandla. 1972-1987. Kraków: Wydawnictwo Literackie, 2013.

LEM, Stanisław. Tajemnica Chińskiego pokoju. Kraków: Universitas, 1996.

MARTINS, Hermínio, Hegel-Texas. Issues in the Philosophy and Sociology of Technology, in: H. Martins (ed.) Knowledge and Passion - Essays in Honour of John Rex, London: I. B. Tauris, 1993.

VONNEGUT, Kurt. „Ludzie, czy to tylko żarty?” In: Lem w oczach krytyki swiatowej. Wybór i opracowanie Jerzy Jarzębski. Kraków: Wydawnictwo Literackie, 1989. 